\title{
Collaborative note-taking affects cognitive load: the interplay of completeness and interaction
}

\author{
Jamie Costley ${ }^{1} \cdot$ Mik Fanguy $^{2,3}$ (D)
}

Accepted: 2 March 2021 / Published online: 19 March 2021

(c) The Author(s) 2021

\begin{abstract}
Studies showing improved learning performances for students who take notes collaboratively have speculated that sharing this task among group members may reduce the extraneous cognitive burden placed on each member. Therefore, a study $(n=171)$ was conducted in the context of a flipped scientific writing course to examine the effects of collaborative note-taking on student's levels of cognitive load. Students in the course were divided into two groups, with members of the treatment group being directed to take collaborative notes in a shared online document and members of the control group receiving no such instructions. The study also measured the level of collaboration the collaborative note-takers engaged in, as well as the level of completeness of the notes that they produced. The results showed that, firstly, the treatment group reported higher levels of both germane and extraneous cognitive load compared to those of the control group, meaning that collaborative note-takers experienced higher levels of understanding of course content as well as increased confusion. Secondly, the level of collaboration was positively and significantly correlated with levels of germane load (understanding), but not with extraneous load (confusion). Thirdly, no correlation was found between completeness of notes and cognitive load. Accordingly, the authors suggest that collaborative note-taking is worthwhile, as the gains to students' understanding of course content outweigh the disadvantages of increased confusion.
\end{abstract}

Keywords Cognitive load · Note-taking $\cdot$ Collaboration $\cdot$ Flipped instruction · Online video lectures

Mik Fanguy

mik@kaist.edu

Jamie Costley

jcostley@hse.ru

1 Institute of Education, National Research University Higher School of Economics, Moscow, Russia

2 School of Humanities and Social Sciences, Korea Advanced Institute of Science and Technology (KAIST), 291 Daehak-ro, Guseong-dong, Yuseong-gu, Daejeon 34141, South Korea

3 Department of Educational Research, University of Lancaster, Lancashire, UK 


\section{Introduction}

Teachers and researchers regularly assert the benefits and importance of collaboration in higher education. However, the results of research into the effectiveness of group work on student learning and student performance have been mixed (Kirschner et al., 2011a, $2011 \mathrm{~b}$ ). The field of education needs to understand how collaboration can lead to processes that improve the individual's understanding and application on a particular topic in a collaborative setting (Reis et al., 2018). It has been suggested that collaboration in learning situations is important not only for the group, but also for the group's individual members (Hung, 2013). Collaboration promotes active learning through information sharing and knowledge construction (Chen et al., 2017). Furthermore, research has shown that collaboration may make students more persistent, efficient, and motivated (Laux et al., 2016).

Group note-taking in online situations is an area of increasing research in the field of education (Veletsianos et al., 2016). Group work may lead to higher quality notes or learning artifacts, an improved ability to gain fruitful insights when reviewing them (DeChurch $\&$ Mesmer-Magnus, 2010), and/or deeper and higher order learning and cognitive development (Guertin, 2016). Note-taking has two primary functions from this perspective. The first is the storage of information. Students write down the information, so they may easily access it for future reference and ease of recall (Biggers \& Luo, 2020). In this respect notetaking differs from other forms of collaboration in that the product of group note-taking is of greater relative value that of the products of other types of collaboration. In classroom settings, group work is often assigned for the purpose of engaging learners in collaborative processes that may improve their learning, more than for the production of a high quality document. However, notes are often actively used by learners and therefore have value over and above the processes of collaboration that occurred during their construction. The second function is that of encoding. For encoding, the process itself of writing the notes will help with the recall of the information (Peper \& Mayer, 1978). The reason why collaborative note-taking can be implemented is therefore twofold. The first reason is that simultaneously comprehending, writing down, and learning from contents is challenging (Chen, 2013) and doing this collaboratively may reduce the extraneous cognitive burden students feel. Students may divide the labor of note-taking as well to produce a more detailed set of notes than they would otherwise have made by themselves (Jansen et al., 2017). Furthermore, the ability for students to focus on particular parts of the contents and the processes inherent in collaborative note-taking may lead to students gaining a better understanding of the contents (Baldwin et al., 2019).

There has been some concern within educational research that comparing the performance of learners in groups with that of learners individually may ignore how collaboration affects the cognitive processes of students engaged in group work (Jansen et al., 2017). Cognitive load is largely concerned with how learners receive information and then process it from their short-term to their long-term memories (Ayres, 2020). From the perspective of cognitive load theory, limitations in an individual's ability to process information can be overcome through collaboration with others who have different knowledge or skills, or who can take some of the mental workload required to complete a task (Kirschner et al., 2011a, 2011b).

There are three fundamental components of cognitive load: intrinsic load, extraneous load, and germane load. Intrinsic load mostly deals with how complex the contents are for students to comprehend, extraneous load deals with aspects of information transfer that decreases comprehension, and germane load represents the information that learners have 
absorbed (Sweller et al., 1998). Furthermore, from a cognitive load perspective, there are processes inherent in learner-to-learner interactions that help to develop learners' understanding of a topic (Guertin, 2016). Therefore, we can see collaboration from two perspectives. The first is that the process of collaboration produces a better quality final learning product that the student can refer to in order to support and scaffold his/her learning. The second is that it is the processes of interaction themselves that lead to greater levels of learning for the individual student.

While there has been a lack of research into collaborative note-taking, two controlled experiments found that students who actively took notes collaboratively showed improved learning performance compared to those who took notes individually (Baldwin et al., 2019; Orndorff, 2015). The common explanation in these two studies was that the students seemed to benefit from sharing the workload of note-taking so that they were better able to focus on the lecture being presented. Thus far, no study has measured students' levels of cognitive load when engaged in collaborative note-taking. Research into this issue will help add to the field's understanding of collaboration in general and collaborative notetaking specifically.

\section{Literature review}

\section{Collaboration and cognitive load}

Cognitive load theory is a useful way of understanding how collaboration in higher education takes place and how it may improve or detract from student learning (Kirschner et al., 2011a, 2011b). The long-term memory can accumulate potentially limitless amounts of information; however, the working memory is easily overwhelmed, particularly if information is poorly presented, overly complex, or given in large amounts (De Jong, 2010). The process of externalizing information to other group members may have benefits in reducing the negative impacts of cognitive load and in helping learners to construct a shared conceptual understanding of the contents (Kirschner et al., 2010).

From the perspective of cognitive load theory, group work is effective when information is presented and processed in a way that allows the clearest and most comprehensible transfer, and minimizes confusing transfer of information and unneeded interaction, which would be manifested in high levels of extraneous cognitive load (Jansen et al., 2017; Kirschner et al., 2010). Groups engaging in collaborative learning can be thought of as systems for processing and sharing the knowledge held by the individual members of the group (Jansen et al., 2017). Collaboration has been shown to have varied effects on cognitive load. Liao et al., (2019) show that collaboration does not affect the perceived content complexity for learners (intrinsic load), though it does increase the amount of extra information the learners have to take in when they interact (extraneous load). However, collaboration has also been shown to increase the amount of information learners are attempting to process (germane load), which shows that collaboration may have conflicting effects on a learner's level of cognitive load, depending on the type of cognitive load measured.

\section{The effects of collaborative note-taking on learning}

Learners may take notes while listening to a lecture in order to store relevant information so that it can be accessed later when needed. This storage of information relieves the 
student of some of the difficulty of recalling salient points from the content (Biggers \& Luo, 2020). Despite such benefits of individual note-taking, it is a cognitively demanding activity (Piolat et al., 2005). Taking notes while listening or reading is sufficiently challenging to overwhelm the learner's working memory in some cases (Chen, 2013), in part because the instructor controls the speed and flow of information, while the student must endeavor to keep up.

However, with the increasing prevalence of online learning environments, opportunities abound for learners, rather than instructors, to control the flow of information, and this is referred to as learner-controlled pacing. In learning environments where lectures are provided in the form of pre-recorded videos, students can exert some control over the speed and flow of information through lecture-viewing strategies such as pausing, rewinding, rewatching, frame-seeking, and changing the playing speed of the video. Studies have shown that students who frequently engage in such practices can increase their understanding of the learning content and decrease their confusion (Costley et al., 2020), which may, in turn, reduce the aforementioned difficulties of note-taking.

Concurrent with the rise of online and blended instruction, collaborative learning has increased in popularity, so that note-taking as pair- or group-work has become more prevalent (Petko et al., 2019). It has been shown that both long- and short-term recall are improved when learners are given the chance to work together reviewing notes in pairs (Ruhl et al., 1987). Furthermore, when learners generate notes in pairs, notes have been found to be more original than when notes are taken by just a single learner (Luo et al., 2016). There is some evidence that having access to a complete set of notes produced by another student may be more beneficial than taking notes oneself (Kiewra, 1989). This may be because taking notes places a cognitive demand on the note-taker while trying to understand a lecture, while the student who was borrowing the notes would have no such stress.

However, there may be challenges when taking notes in groups from a cognitive load perspective. There may be a cognitive transaction cost that causes errors, conflicts, or an increase in cognitive workload (Kirschner et al., 2010). There is some evidence that trying to combine all of the actions needed to write notes (comprehension, writing, and learning) while collaborating can be challenging for students and lead to overburdening their working memory (Chen, 2013). If a learner is attempting to follow along with a lecture while taking notes as well as trying to look at another student's notes, the cognitive resources required may be too great for the learner to manage (Piolat et al., 2005). The ability for learners to give each other feedback has been shown to help with learners' retention and understanding of learning materials (Shute, 2008). However, learners who lack the skills to self-regulate may struggle with complex information when asked to collaborate in groups (Miller \& Hadwin, 2015).

\section{The effects of interaction on learning}

The amount that learners collaborate affects the amount that group members gain from an information processing perspective (Rienties et al., 2009). Generally speaking, this translates to greater contributors gaining higher levels of knowledge from the collaborative activity (Carss, 2007). There are several reasons why this might be the case. Firstly, it has been shown that group work leads to more detail-oriented learning (Carlsmith \& Cooper, 2002). Secondly, the self-explanation principle posits that there will be an improvement in retention if one has to explain a concept to another (van Merriënboer \& Sweller, 2010). Thirdly, if learners interact with content as a group, they will be more likely to be reflective 
about their own ideas regarding the contents, which causes more meaningful learning (Baker \& Lund, 1997). The importance of learners' emotional states and social-emotional interactions on group interaction has been explored in the context of group note-taking. Such research has shown how learners require a certain specific dynamic to get the full gains from learner-to-learner collaboration (Reis et al., 2018). One of the dangers is the frustration students can feel from dealing with team members who put in less effort or who are difficult to communicate with when collaborating on a project (Capdeferro \& Romero, 2012).

Interacting in a written form about the classes that they take has been shown to benefit learners (Hung, 2018). Furthermore, learners themselves see the benefits of written interaction, reporting increased attention spans, high levels of enjoyment, and higher perceived levels of learning (Craig et al., 2007; Li et al., 2014; Weisz et al., 2007; Wise \& Cui, 2018). Learners who are engaged in more iterative and dynamic forms of interactions have been shown to have increased learning gains (Noguera et al., 2018). Students engaging in more interaction and a higher amount of group processes can achieve greater cognitive gains than those who do not. However, it has been shown that there is a tradeoff in terms of interaction in simpler tasks, as the cognitive costs of interacting may outweigh the benefits (Kirschner et al., 2010).

\section{The effect of note-taking quality on learning}

While group interactions may lead to higher quality group work, it may be the case that group outcomes are more important with regard to learning. Some authors have warned against a final product focus when looking at collaboration, as content-mastery is often the goal of much group work, not the final product the group creates (Yim et al., 2017). It has been shown empirically that successful group work leads to more retention of contents (Barron, 2003). Specifically, there is evidence in science and engineering classes that groups that have a high level of performance will have members who perform better in individual tasks related to their coursework (Springer et al., 1999). One way of looking at learners' collaboration when note-taking is the degree of completeness of the notes (Ruhl $\&$ Suritsky, 1995). Some research shows that learners who produce more complete notes learn more (Raver \& Maydosz, 2010). However, there is some debate regarding this, with some research showing that notes that transcribe the lectures contents rather than paraphrasing them result in lower student outcomes (Mueller \& Oppenheimer, 2014). It may be the case that not all forms of interaction lead to the completion of the learner's task or the solving of a problem (Sinha et al., 2015). In this type of situation, off-task interactions that are not focused on task completion may hinder the cognitive benefits of collaboration.

\section{The effects of interaction on note-taking quality}

There is some evidence that shows that the ways in which learners interact affect their ability to complete a task to a high level or to solve a problem (Dias et al., 2017). Groups who successfully complete tasks often engage in more types of interaction and more total interaction than groups who do not (Ja, 2018). In some cases, online student interactions can be more off-task than those in offline class, which may be because virtual communities are less moderated and more emergent than offline interactions (Kent et al., 2016). In this situation, more interaction may not benefit the students' final product. However, most research on this question shows that the amount of online 
interactions are related with the quality of the interactions (Wilkinson \& Huberman, 2007), and other evidence suggests that the depth of a learner's contribution to collaborative work is related to the amount they have looked at others' work (Kent et al., 2016). There is evidence that collaboration in online mind-mapping leads to a higherquality, better-developed final product by the students (Dias et al., 2017). This is evidence for the value of collaboration in creating a high-quality student artifact. Furthermore, quality of work is directly affected by how learners are responding to others' work, not just reflecting on their own previously written contributions (Kent et al., 2016). This type of active engagement with the learning environment has been shown to lead to greater learning outcomes for students with more active engagement with the community, leading to greater levels of knowledge (Freeman et al., 2014).

In the case of collaborative note-taking or collaborative writing more specifically, there is a lack of research regarding how collaboration might affect the quality of a set of notes. Previous research has divided student writing into four main collaborative styles that vary in the degree and manner of interaction (Yim et al. 2017). This research suggests that strategies with low levels of interaction (Divide and Conquer) resulted in more high-quality pieces of writing. In this strategy, learners chunk off parts of the task and then work individually to complete it with a low amount of editing of others work or interaction with other members. This result suggests that more interaction between group members may not lead to higher-quality final products.

\section{The present study}

Existing research suggests that taking notes collaboratively will benefit learners' levels of cognitive load and improve the quality of the notes they take compared to taking notes individually. Therefore, the present study investigates the relationships between cognitive load and aspects of collaborative note-taking. The present research looks at two groups of students: one group is engaged in collaborative note-taking organized by their instructor, and the other group is not. Furthermore, within the group that is collaborating, the amount and quality of the collaboration will be examined. Therefore, this study proposes six hypotheses:

(1) The group that is engaged in collaborative note-taking will have higher levels of germane cognitive load.

(2) The group that is engaged in collaborative note-taking will have lower levels of extraneous cognitive load.

(3) Within the group that is engaged in collaborative note-taking, students in groups that interact more will have higher levels of germane cognitive load.

(4) Within the group that is engaged in collaborative note-taking, students in groups that interact more will have lower levels of extraneous cognitive load.

(5) Within the group that is engaged in collaborative note-taking, those that are in groups with more complete notes will have higher levels of germane cognitive load.

(6) Within the group that is engaged in collaborative note-taking, those that are in groups with more complete notes will have lower levels of extraneous cognitive load. 


\section{Methods}

\section{Participants and context}

The present study examined the levels of cognitive load of 171 students enrolled in a Scientific Writing course at a large university in South Korea. The students who participated in this study were all graduate students majoring in a variety of STEM fields. These participants were divided into two groups, with one being treatment (74 students) and the other control (97 students). As can be seen in Table 1, the gender breakdowns of the treatment and control groups were similar, with both having $27 \%$ of their members being female. Furthermore, the age ranges and average ages of the students were also similar with the average age in the treatment group being 26.97, and the average age in the control group being 26.61 (Table 1).

The goal of the scientific writing course was to teach masters and $\mathrm{PhD}$ students how to compose a manuscript on the results of their research for publication in an academic journal in their field. In order to increase scheduling flexibility for graduate students, who are typically required to spend long hours in their research laboratories, the course was presented in flipped format (Fanguy et al., 2021). The semester-long course consisted of ten instructional weeks. During each instructional week, students were required to watch a batch of four to nine pre-recorded lecture videos. The videos were provided on the course learning management system (LMS) and could be viewed at the learners' convenience as many times as desired. After viewing the videos, students would then take a timed online multiple-choice quiz that tested their recall and understanding of the content they had viewed during the instructional week.

After these online components of the course were completed, students attended a 90-min face-to-face (F2F) class meeting with the course instructor. During these F2F classes, which took place once a week, students participated in collaborative writing activities that corresponded to the instruction students had received from the videos they had just watched during the online component of the course. These activities were designed by the instructor to allow students to demonstrate their mastery of the instructional contents from the lecture videos and to improve students' ability to communicate their research through writing.

\section{Procedures}

Among the nine course sections examined in the present study, five sections $(n=97)$ comprised a control group of students who were given no special instructions regarding

Table 1 The gender and age of the participants

\begin{tabular}{lllcll}
\hline & Gender & Frequency & Percent & Age & \\
\hline Control & Female & 26 & 26.8 & Min & 22 \\
& Male & 71 & 73.2 & Max & 45 \\
& Total & 97 & 100.0 & Mean & 26.61 \\
Treatment & Female & 20 & 27.0 & Min & 22 \\
& Male & 54 & 73.0 & Max & 43 \\
& Total & 74 & 100.0 & Mean & 26.97 \\
\hline
\end{tabular}


note-taking. The remaining four sections $(n=74)$ comprised the treatment group who were asked to take collaborative notes on the concepts from the online lecture by using Google Documents in small groups of three to five students. These Google Documents were created and monitored by the professor in charge of the class, and there was one Google Document corresponding to each of ten instructional weeks of the course for each collaborative note-taking group. Accordingly, each note-taking group collaborated on ten Google Documents during the semester. There were ten online multiple-choice quizzes during the semester, with each corresponding to one instructional week of video instruction. Students in the treatment group would contribute to the collaborative notes at their convenience (asynchronously) and were allowed and encouraged by the instructor to consult these group notes while taking quizzes. Similarly, students in the control group were also allowed to consult their notes, if they had taken any, while taking the online quizzes.

All students were thoroughly informed of their right to opt out of the study at any point, and the study was approved through an institutional review board (IRB) of the university where it was conducted. At the end of the course, students were requested to fill out a consent form that was part of the IRB. This consent form also contained the survey items used for the cognitive load measures that will be explained in the next section.

\section{Measures}

\section{Cognitive load}

In order to assess the students' cognitive load, surveys were given containing items from Leppink et al., (2013) paper, The development of an instrument for measuring cognitive load. In this paper, Leppink et al., describe the functions and applications of the three primary elements of cognitive load (extraneous, germane, and intrinsic) and provide survey items to measure them. The present study utilized ten of these items. All items were based on a Likert-like scale between 1 and 7, with 1 being strongly disagree, and 7 being strongly agree. For measuring germane load, the following were used: (1) the lecture really enhanced my understanding of the topic; (2) the lecture really enhanced my knowledge and understanding of the of the class subject; (3) the lecture really enhanced my understanding of the concepts associated with the class subject; and (4) the lecture really enhanced my understanding of concepts and definitions. The Cronbach's Alpha for the germane load construct was .931. To measure extraneous load, the following were used: (1) the explanations during the lecture were very unclear; (2) the explanations were, in terms of learning, very ineffective; and (3) the explanations were full of unclear language. The Cronbach's Alpha for the extraneous load construct was .824. Lastly, the following items were adapted and used for measuring intrinsic load with regard to lecture videos: (1) the topic/topics covered in the lecture was/were very complex. (2) the lecture covered information that I perceived as very complex; and (3) the lecture covered concepts and definitions that I perceived as very complex. The Cronbach's Alpha for the intrinsic load construct was .877 .

\section{Collaboration in note-taking}

This study used an index to assess the amount of written collaboration students engaged in when composing their notes. Five collaborative variables were scored, and these scores were combined into a total collaboration index score. The four variables of collaboration included in the index are described below. 


\section{Turn-taking}

Individual members within each group were asked to write their notes in a unique font color in order to distinguish their writing from the writing of other group members. A turn was counted each time the font color (or "authorship") changed within a note-taking document, and the number of turns taken by a group served as the group turn-taking variable.

\section{Editing text written by fellow group members}

The edits variable was calculated by tallying the total number of edited characters by all group members, not including self-edits.

\section{Volume}

The volume variable was calculated as the total number of words written by all the group members within a note-taking document after editing.

\section{Sessions}

In order to calculate the number of sessions used to construct the online collaborative notes, the number of log-ins by each group member that resulted in any amount of writing were tallied. In this way, the number of sessions for each member in a group could be added up to create a total group sessions variable.

\section{Completeness of collaborative notes}

Completeness is a common measure of the quality of notes taken by students (Howe, 1970; Locke, 1977; Ruhl \& Suritsky, 1995). In the present study, the completeness of the collaborative notes taken by student groups was evaluated using a technique adapted from the one used by Raver and Maydosz (2010). The instructor generated summaries of the concepts explained in each of the 56 lecture videos included in the course, and these summaries were used to create ten rubrics to evaluate the completeness of ten corresponding sets of notes taken in each instructional week of the course by each student group. Each rubric contained a list of "meaningful units" of information given in each lecture video for a given instructional week in chronological order. The course instructor and teaching assistant reviewed each note-taking document in order to verify how many meaningful units were recorded by each student group. Each time a meaningful unit was identified, a " 1 " was awarded in the rubric spreadsheet next to the corresponding rubric item. In cases where a meaningful unit was omitted from the notes, a score of " 0 " was given on the rubric next to the corresponding item. Meaningful units that were recorded incorrectly or with error were given a score of " 0 ". After the instructor and teaching assistant finished rating all of the collaborative notes for a given week, the course instructor compared the rubric spreadsheets to find inconsistencies in grading between himself and the teaching assistant. In such cases, the instructor reread the disputed section of the notes and considered whether the meaningful unit had been properly represented by the students. Once disputed items were resolved in this manner, 


\begin{tabular}{|c|c|c|c|c|c|c|c|c|c|}
\hline 1 & Code & Meaningful Unit & B1 & B2 & B3 & B4 & D1 & D2 & D3 \\
\hline 783 & W13_V3_M34 & - Caveats about limitations of a study, missing controls, etc. & 1 & 1 & 1 & 0 & 1 & 0 & 0 \\
\hline 784 & W13_V3_M35 & How to choose your target journal: & 1 & 0 & 1 & 1 & 1 & 1 & 0 \\
\hline 785 & W13_VI_M36 & Honestly evaluate your findings: & 1 & 1 & 1 & 1 & 1 & 1 & 0 \\
\hline 786 & W13_V3_M37 & How big an advance are your findings? & 1 & 1 & 1 & 1 & 1 & 1 & 0 \\
\hline 787 & W13_V3_M38 & How high can you realistically aim? & 1 & 1 & 1 & 1 & 1 & 1 & 0 \\
\hline 798 & W13_V3_M39 & Check aims and scope of several journals: & 1 & 1 & 1 & 1 & 1 & 1 & 0 \\
\hline 789 & W13_V3_M40 & Who reads them? & 1 & 1 & 1 & 1 & 1 & 1 & 0 \\
\hline 790 & W13_V3_M41 & Who published in them? & 1 & 1 & 1 & 1 & 1 & 1 & 0 \\
\hline 791 & W13_V3_M42 & How much do they charge? & 1 & 1 & 1 & 1 & 1 & 1 & 0 \\
\hline 792 & W13_V3_M43 & What type of studies have they published recently? & 1 & 1 & 1 & 1 & 1 & 1 & 0 \\
\hline 793 & W13_VI_M44 & Novelty Aims and Scope & 0 & 0 & 0 & 0 & 0 & 0 & 0 \\
\hline 794 & W13_V3_M45 & Significance Impact Factor & 0 & 0 & 0 & 0 & 0 & 0 & 0 \\
\hline 795 & W13_V4_M1 & Reason 1: Results are not sound: & 1 & 1 & 1 & 1 & 1 & 1 & 1 \\
\hline 796 & W13_V4_M2 & Further controls needed. & 1 & 1 & 1 & 1 & 1 & 1 & 1 \\
\hline 797 & W13_V4_M3 & Sample size is too small. & 1 & 1 & 1 & 1 & 1 & 1 & 0 \\
\hline 798 & W13_V4_M4 & Control samples are inappropriate. & 1 & 1 & 1 & 1 & 1 & 1 & 0 \\
\hline 790 & W13_V4_M5 & Further statistical analysis neøded: & 1 & 1 & 1 & 1 & 1 & 1 & 1 \\
\hline 800 & W13_V4_M6 & Statisticians advice on the appropriate tests. & 1 & 1 & 1 & 1 & 1 & 1 & 0 \\
\hline 801 & W13_V4_M7 & Sample sizes too small to give meaningful results. & 1 & 1 & 1 & 1 & 0 & 1 & 0 \\
\hline 802 & W13_V 44 M8 & Methods used are inappropriate: & 1 & 1 & 1 & 1 & 1 & 1 & 1 \\
\hline
\end{tabular}

Fig. 1 Screenshot of the rubric used in this study to evaluate notetaking completeness

Table 2 Cognitive load means and t-test for the treatment and control groups

\begin{tabular}{llll}
\hline Experimental & GL & EL & IL \\
\hline $\begin{array}{llll}\text { Control } \\
\text { Mean }\end{array}$ & 30.2371 & 5.7938 & 10.9691 \\
$N$ & 97 & 97 & 97 \\
$S D$ & 7.80995 & 3.72474 & 5.86915 \\
Treatment & & & \\
Mean & 34.4015 & 8.8031 & 11.3707 \\
$N$ & 74 & 74 & 74 \\
$S D$ & 4.16837 & 5.40259 & 6.69408 \\
$\mathbf{t}$ test & & & \\
$t$ value & -4.156 & -4.307 & -.417 \\
$p$ value & .000 & .000 & .677 \\
Mean difference & -4.16443 & -3.00927 & -.40158 \\
Total & & & \\
Mean & 32.0393 & 7.0961 & 11.1429 \\
$N$ & 171 & 171 & 171 \\
$S D$ & 6.79616 & 4.75440 & 6.22370 \\
\hline
\end{tabular}

the ten rubrics were combined into one large spreadsheet that contained a total of 930 meaningful units from all of the online lecture videos included in the course. To calculate the notetaking completeness for each notetaking group, the number of meaningful units included in the 10 collaborative note-taking documents was totaled for a completeness score with a maximum of 930. Figure 1 shows a screenshot of the notetaking completeness rubric used in the present study.

\section{Results}

The first step in the research was looking at the difference in mean levels of the three types of cognitive load for the control and treatment groups. As can be seen in Table 2, there were some differences and some similarities in the means for the three different cognitive load constructs between the treatment and control groups. In terms of germane cognitive 
load, the mean for the treatment group was higher (34.40) than the control's mean (30.24). As with germane cognitive load, in the case of extraneous cognitive load, the treatment's mean was higher (8.80) than the control group mean (5.70). In the case of intrinsic cognitive load, both the control (10.97) and treatment groups (11.37) had similar averages for their means of intrinsic load.

Following an initial investigation of the mean differences in levels of germane, extraneous, and intrinsic cognitive load, two sample student t-testing was done to understand if the differences found were statistically significant (Table 2). The treatment group had a 4.16 higher germane cognitive load mean than the control group (hypothesis 1 is held), and this difference was statistically significant $(\mathrm{t}=-4.156, \mathrm{p}<.000)$. The treatment group also had a 3.01 higher extraneous load mean than the control group (hypothesis 2 is held). The treatment and control groups' extraneous cognitive load difference was also statistically significant $(\mathrm{t}=-4.307, \mathrm{p}<.000)$. The difference between the treatment and control group's level of intrinsic cognitive load was .40 , and this difference was not statistically significant $(\mathrm{t}=-.417, \mathrm{p}=.677)$.

To further understand the effect engaging in collaborative note-taking has on cognitive load, the correlations between germane cognitive load, extraneous cognitive load, the amount of collaboration, and the completeness of notes were calculated. This was done to understand the effects of more collaboration within the treatment group. Of importance to the present study is the relationships between the aspects of cognitive load and the amount of collaboration and the completeness of notes. As can be seen in Table 3, the amount of collaboration had a positive relationship with both germane and extraneous cognitive load. However, only the correlation between amount of collaboration and germane load was statistically significant (hypothesis 3 is held), while the relationship between amount of collaboration and extraneous load was not (hypothesis 4 is rejected). Furthermore, while both germane and extraneous load had a positive relationship with the completeness of notes, these correlations were not statistically significant and were smaller than the effect of the amount of collaboration (hypotheses 5 and 6 are rejected).

\section{Discussion and conclusion}

The first result of importance is the effect the treatment had on student levels of germane cognitive load. The present study compared students who took collaborative online notes to those with no online student-to-student interaction and found that students in the collaborative notes condition had higher mean levels of germane load. This shows that students who engaged in online collaborative notes rated their schema development and perceptions of

Table 3 Relationship between collaboration and artifact with GL in the treatment group $(n=74)$

\begin{tabular}{lcccc}
\hline & Germane load & Extraneous load & $\begin{array}{l}\text { Amount of col- } \\
\text { laboration }\end{array}$ & Completeness \\
\hline Germane load & 1 & & & \\
Extraneous load & $-.374^{\mathrm{a}}$ & 1 & 1 & 1 \\
Collaboration & $.243^{\mathrm{a}}$ & .071 & $.387^{\mathrm{a}}$ & 1 \\
Completeness & .081 & .055 & & 1 \\
\hline
\end{tabular}

${ }^{\mathrm{a}}$ Correlation is significant at the .05 level 
cognitive improvement as being higher. This falls in line with other research on the topic of collaboration and cognitive load that has shown that collaborative groups are information processing systems that may help students learn as they interact (Jansen et al., 2017). This positive effect on germane load may be generated by several factors that collaboration promotes such as the production of more original notes than if note-taking was done alone (Luo et al., 2016), encoding of information by others (Kiewra, 1989), scaffolding of difficult information (Costley \& Lange, 2018), and the self-explanation principle which shows that students who explain something to themselves and/or others will have increased levels of germane cognitive (van Merrienboer \& Sweller, 2010). Another factor that may lead to higher levels of germane load is that when learners can give each other feedback, they tend to retain and understand more of what they are taught (Shute, 2008).

The second result of value from this study is the finding that levels of extraneous cognitive load were higher in the collaborative note-taking condition. This finding shows that collaborative note-taking increased the student perceptions of how confusing the content was that was delivered to them. This result suggests that while group work increases learning (in the form of germane cognitive load), it also increases the mental strain that students perceive. This finding fits in with other research that claims that while collaboration is beneficial, it does increase the total amount of information students have to consume, which may increase extraneous load (Liao et al., 2019). There are several reasons for this. The first is the transaction cost of interaction (Kirschner et al., 2009). The second is that there is an increase in total actions students need to take as collaborators (Chen, 2013). Finally, trying to comprehend the contents from an instructor as well as information from another student may possibly overburden someone taking notes in a group (Piolat et al., 2005).

After establishing that there was a difference between a no-collaboration condition and a collaboration condition, the effects of the amount of collaboration were investigated. To do this, both the amount of collaboration and the quality of collaboration were correlated with the cognitive load constructs. The results showed that the more collaboration increased, the higher the levels of germane cognitive load. This result falls in line with other research suggesting that the amount of collaboration done within a group will positively affect the amount learners gain from that group (Noguera et al., 2018; Rienties et al., 2009). This is because collaboration leads to learners noticing more detail (Carlsmith \& Cooper, 2002), reflecting more on the contents (Baker \& Lund, 1997), and regulating their social-emotional states (Reis et al., 2018). These effects may be particularly strong in this case, as writing specifically has been shown to benefit learners (Hung et al., 2018). For these reasons, the present study supports research that shows that increasing levels of collaboration will benefit learners' levels of germane cognitive load. However, interestingly, the amount of collaboration did not result in changes in the level of extraneous load, suggesting that the administration or set up of collaboration may be the cause of extraneous load not the collaboration itself.

Curiously, there was no statistically significant relationship between the completeness of notes and either germane cognitive load or extraneous cognitive load. This contradicts some previously published studies that suggest that higher quality group work and more complete notes lead to higher levels of information retention (Barron, 2003; Raver \& Maydosz, 2010). Furthermore, for science and technology students specifically (which the current study is made up of), more high-quality, complete final products lead to individual perceptions of high levels of learning (Springer et al., 1999). The results of the present study fall in line with research that suggests that we must look at group work as a process of content mastery, not as simply the completion of a task (Yim et al. 2017). Note-taking in the present study was a task that required the repetition of large chunks of information that 
may have reduced the effect of completeness levels on student learning in the form of germane cognitive load. This issue of simple transcribing of contents not leading to learning gains has been noted in the literature before (Mueller \& Oppenheimer, 2014).

The results showing that both germane and extraneous load are higher give pause as to the value of online collaborative note-taking. The higher levels of germane load can be seen as beneficial, while the higher levels of extraneous load can be seen as detrimental. However, considering this conflict, the authors of present study suggest it is still beneficial to implement collaborative note-taking. The clear gains that students reported in germane cognitive load outweigh the possible downsides of higher levels of extraneous load. It seems from the results of the present study, that while the students are finding collaborating more difficult to process than not collaborating, those difficulties do not negatively impact the levels of learning in the form of germane cognitive load. Even though students find it more difficult and confusing, they did feel like they learned more in the collaborative note-taking condition. A large body of research shows the importance of presenting information in a way that minimizes extraneous processing (Jansen et al., 2017; Kirschner et al., 2009), so future research could investigate how group work can be set up and designed to reduce the extraneous processing of collaboration.

Further to this, as increasing amounts of collaboration do not increase levels of extraneous load, it seems plausible that it is the initial tasks of setting up the collaboration that may cause the extraneous cognitive load to be higher when comparing the control group to the note-taking group, but not to vary within the note-taking group. It has been shown that not all forms of interaction lead to learning (Sinha et al., 2015), and it may also be the case that not all forms of interaction cause increases in extraneous load. Future research could also look at how different parts of the tasks that are undertaken as part of collaboration affect students' levels of extraneous processing. Engaging in online collaboration is useful; however, care must be taken to minimize extraneous cognitive load. When instructors set up learning environments in which the technology is imbedded to promote student-tostudent interaction, then those learning environments will result in creating greater degrees of interaction than if the technology is used ad hoc (Borokhovski et al., 2016).

The main limitations of this paper are that it cannot look more directly at the effects that are causing the changes in cognitive load levels and that the cognitive load levels are selfreported measures. The authors believe that the relationships found in the present study represent a real effect of online interaction on students' levels of cognitive load; however, with the cognitive load measures being self-reported, there is always the possibility of misunderstanding or misinterpreting the results. While the use of survey items in general and the survey items used in the present are well subscribed, there can still be a possible issue there. Furthermore, this study looks at a specific type of collaboration in the form of collaborative note-taking. It may be the case that other forms of collaboration do not influence cognitive load to the same degree. For this reason, one must be careful in generalizing the findings of the present study to other forms of collaboration. Despite these limitations, this study allows us to see that not only do experimental conditions with online interaction have higher levels of germane cognitive load, but they also have higher levels of extraneous cognitive load. Furthermore, these results are somewhat duplicated within the collaboration condition with students with higher levels of collaboration reporting higher levels of germane load. However, this effect does not extend to increased levels of extraneous cognitive load. This study shows the value and dangers of providing online interaction for learners and that once online interaction is put in place, it should be promoted. 


\section{Declarations}

Conflict of interest The authors declare that they have no conflict of interest.

Ethical approval The research methods used in this study involved human subjects, so the authors applied for and received ethical approval from an IRB at the institution where the research was carried. The research adheres to the ethical policies of the institution. All participants were informed of their rights and participated voluntarily.

Open Access This article is licensed under a Creative Commons Attribution 4.0 International License, which permits use, sharing, adaptation, distribution and reproduction in any medium or format, as long as you give appropriate credit to the original author(s) and the source, provide a link to the Creative Commons licence, and indicate if changes were made. The images or other third party material in this article are included in the article's Creative Commons licence, unless indicated otherwise in a credit line to the material. If material is not included in the article's Creative Commons licence and your intended use is not permitted by statutory regulation or exceeds the permitted use, you will need to obtain permission directly from the copyright holder. To view a copy of this licence, visit http://creativecommons.org/licenses/by/4.0/.

\section{References}

Ayres, P. (2020). Something old, something new from cognitive load theory. Computers in Human Behavior. https://doi.org/10.1016/j.chb.2020.106503

Baker, M., \& Lund, K. (1997). Promoting reflective interactions in a CSCL environment. Journal of Computer Assisted Learning, 13(3), 175-193. https://doi.org/10.1046/j.1365-2729.1997.00019.x

Baldwin, M. P., Fanguy, M., \& Costley, J. H. (2019). The effects of collaborative note-taking in flipped learning contexts. Journal of Language and Education, 5(4), 25-35. https://doi.org/10.17323/jle.2019. 9726

Barron, B. (2003). When smart groups fail. The Journal of the Learning Sciences, 12(3), 307-359. https:// doi.org/10.1207/S15327809JLS1203_1

Biggers, B., \& Luo, T. (2020). Guiding students to success: A systematic review of research on guided notes as an instructional strategy from 2009-2019. Journal of University Teaching \& Learning Practice, $17(3), 12$.

Borokhovski, E., Bernard, R. M., Tamim, R. M., Schmid, R. F., \& Sokolovskaya, A. (2016). Technologysupported student interaction in post-secondary education: A meta-analysis of designed versus contextual treatments. Computers \& Education, 96, 15-28. https://doi.org/10.1016/j.compedu.2015.11.004

Capdeferro, N., \& Romero, M. (2012). Are on-line learners frustrated with collaborative learning experiences? The International Review of Research in Open Distance Learning, 13(2), 26-43. https://doi. org/10.19173/irrodl.v13i2.1127

Carlsmith, K. M., \& Cooper, J. (2002). A persuasive example of collaborative learning. Teaching of Psychology, 29(2), 132-135. https://doi.org/10.1207/S15328023TOP2902_12

Carss, W. D. (2007). The effects of using think-pair-share during guided reading lessons (Thesis, Master of Education (MEd)). The University of Waikato, Hamilton, New Zealand. Retrieved from https://hdl. handle.net/10289/2233

Chen, C. H., Law, V., \& Chen, W.-Y. (2017). The effects of peer competition-based science learning game on secondary students' performance, achievement goals, and perceived ability. Interactive Learning Environments. https://doi.org/10.1080/10494820.2017.1300776

Chen, P. H. (2013). The effects of college students' in-class and after-class lecture note-taking on academic performance. The Asia-Pacific Education Researcher, 22(2), 173-180. https://doi.org/10.1007/ s40299-012-0010-8

Costley, J., Fanguy, M., Lange, C., \& Baldwin, M. (2020). The effects of video lecture viewing strategies on cognitive load. Journal of Computing in Higher Education. https://doi.org/10.1007/ s12528-020-09254-y

Costley, J., \& Lange, C. (2018). The moderating effects of group work on the relationship between motivation and cognitive load. The International Review of Research in Open and Distributed Learning. https://doi.org/10.19173/irrodl.v19i1.3325 
Craig, S. D., Vanlehn, K., Gadgil, S., \& Chi, M. (2007). Learning from collaboratively observing videos during problem solving with andes. Frontiers in Artificial Intelligence and Applications, 158, 554.

De Jong, T. (2010). Cognitive load theory, educational research, and instructional design: Some food for thought. Instructional Science, 38(2), 105-134. https://doi.org/10.1007/s11251-009-9110-0

DeChurch, L. A., \& Mesmer-Magnus, J. R. (2010). The cognitive underpinnings of effective teamwork: A meta-analysis. Journal of Applied Psychology, 95(1), 32-53. https://doi.org/10.1037/a0017328

Dias, S. B., Hadjileontiadou, S. J., Diniz, J. A., \& Hadjileontiadis, L. J. (2017). Computer-based concept mapping combined with learning management system use: An explorative study under the self-and collaborative-mode. Computers \& Education, 107, 127-146. https://doi.org/10.1016/j.compedu.2017. 01.009

Fanguy, M., Lee, S. Y., \& Churchill, D. G. (2021). Adapting educational experiences for the chemists of tomorrow. Nature Reviews Chemistry. https://doi.org/10.1038/s41570-021-00258-5

Freeman, S., Eddy, S. L., McDonough, M., Smith, M. K., Okoroafor, N., Jordt, H., \& Wenderoth, M. P. (2014). Active learning increases student performance in science, engineering, and mathematics. Proceedings of the National Academy of Sciences, 111(23), 8410-8415. https://doi.org/10.1073/pnas. 1319030111

Guertin, L. (2016). Student collaborative note taking during lecture-Encourage or discourage? Retrieved from http://blogs.agu.org/geoedtrek/2016/12/28/collaborative-note-taking

Howe, M. J. (1970). Using students' notes to examine the role of the individual learner in acquiring meaningful subject matter. Journal of Educational Research, 64, 61-63. https://doi.org/10.1080/00220671. 1970.10884094

Hung, I. C., Kinshuk, \& Chen, N. S. (2018). Embodied interactive video lectures for improving learning comprehension and retention. Computers and Education, 117, 116-131. https://doi.org/10.1016/j. compedu.2017.10.005

Hung, W. (2013). Team-based complex problem solving: A collective cognition perspective. Educational Technology Research and Development, 61(3), 365-384. https://doi.org/10.1007/s11423-019-09698-9

Jansen, R. S., Lakens, D., \& IJsselsteijn, W. A. (2017). An integrative review of the cognitive costs and benefits of note-taking. Educational Research Review, 22, 223-233. https://doi.org/10.1016/j.edurev. 2017.10.001

Kent, C., Laslo, E., \& Rafaeli, S. (2016). Interactivity in online discussions and learning outcomes. Computers and Education. https://doi.org/10.1016/j.compedu.2016.03.002

Kiewra, K. A. (1989). A review of note-taking: The encoding-storage paradigm and beyond. Educational Psychology Review, 1(2), 147-172. https://doi.org/10.1007/BF01326640

Kirschner, F., Paas, F., \& Kirschner, P. A. (2011a). Task complexity as a driver for collaborative learning efficiency: The collective working-memory effect. Applied Cognitive Psychology, 25(4), 615-624. https://doi.org/10.1002/acp.1730

Kirschner, F., Paas, F., \& Kirschner, P. A. (2011b). Superiority of collaborative learning with complex tasks: A research note on an alternative affective explanation. Computers in Human Behavior, 27(1), 53-57. https://doi.org/10.1016/j.chb.2010.05.012

Laux, D., Luse, A., \& Mennecke, B. E. (2016). Collaboration, connectedness, and community: An examination of the factors influencing student persistence in virtual communities. Computers in Human Behavior, 57, 452-464. https://doi.org/10.1016/j.chb.2015.12.046

Leppink, J., Paas, F., Van der Vleuten, C. P., Van Gog, T., \& van Merriënboer, J. J. (2013). Development of an instrument for measuring different types of cognitive load. Behavior Research Methods, 45(4), 1058-1072. https://doi.org/10.3758/s13428-013-0334-1

Li, N., Verma, H., Skevi, A., Zufferey, G., Blom, J., \& Dillenbourg, P. (2014). Watching MOOCs together: Investigating co-located MOOC study groups. Distance Education, 35(2), 217-233. https://doi.org/10. 1080/01587919.2014.917708

Liao, C. W., Chen, C. H., \& Shih, S. J. (2019). The interactivity of video and collaboration for learning achievement, intrinsic motivation, cognitive load, and behavior patterns in a digital game-based learning environment. Computers \& Education, 133, 43-55. https://doi.org/10.1016/j.compedu.2019.01.013

Locke, E. A. (1977). An empirical study of lecture note taking among college students. The Journal of Educational Research, 71(2), 93-99. https://doi.org/10.1080/00220671.1977.10885044

Luo, L., Kiewra, K. A., \& Samuelson, L. (2016). Revising lecture notes: How revision, pauses, and partners affect note taking and achievement. Instructional Science, 44(1), 45-67. https://doi.org/10.1007/ s11251-016-9370-4

Miller, M., \& Hadwin, A. (2015). Scripting and awareness tools for regulating collaborative learning: Changing the landscape of support in CSCL. Computers in Human Behaviour, 52, 573-588. https:// doi.org/10.1016/j.chb.2015.01.050 
Mueller, P. A., \& Oppenheimer, D. M. (2014). The pen is mightier than the keyboard: Advantages of longhand over laptop note taking. Psychological Science, 25(6), 1159-1168. https://doi.org/10. $1177 / 0956797614524581$

Noguera, I., Guerrero-Roldán, A. E., \& Masó, R. (2018). Collaborative agile learning in online environments: Strategies for improving team regulation and project management. Computers \& Education, 116, 110-129. https://doi.org/10.1016/j.compedu.2017.09.008

Orndorff, H. N., III. (2015). Collaborative note-taking: The impact of cloud computing on classroom performance. International Journal of Teaching and Learning in Higher Education, 27(3), 340-351.

Peper, R. J., \& Mayer, R. E. (1978). Note taking as a generative activity. Journal of Educational Psychology, 70(4), 514. https://doi.org/10.1037/0022-0663.70.4.514

Petko, D., Schmid, R., Müller, L., \& Hielscher, M. (2019). Metapholio: A mobile app for supporting collaborative note taking and reflection in teacher education. Technology Knowledge and Learning, 24(4), 699-710.

Piolat, A., Olive, T., \& Kellogg, R. T. (2005). Cognitive effort during note taking. Applied Cognitive Psychology, 19(3), 291-312. https://doi.org/10.1002/acp.1086

Raver, S. A., \& Maydosz, A. S. (2010). Impact of the provision and timing of instructor-provided notes on university students' learning. Active Learning in Higher Education, 11(3), 189-200. https://doi. org/10.1177/1469787410379682

Reis, R. C. D., Isotani, S., Rodriguez, C. L., Lyra, K. T., Jaques, P. A., \& Bittencourt, I. I. (2018). Affective states in computer-supported collaborative learning: Studying the past to drive the future. Computers \& Education, 120, 29-50. https://doi.org/10.1016/j.compedu.2018.01.015

Rienties, B., Tempelaar, D., Van den Bossche, P., Gijselaers, W., \& Segers, M. (2009). The role of academic motivation in computer-supported collaborative learning. Computers in Human Behavior, 25(6), 1195-1206. https://doi.org/10.1016/j.chb.2009.05.012

Ruhl, K. L., Hughes, C. A., \& Schloss, P. J. (1987). Using the pause procedure to enhance lecture recall. Teacher Education and Special Education, 10(1), 14-18. https://doi.org/10.1177/0888406487 01000103

Ruhl, K. L., \& Suritsky, S. (1995). The pause procedure and/or an outline: Effect on immediate free recall and lecture notes taken by college students with learning disabilities. Learning Disability Quarterly, 18(1), 2-11. https://doi.org/10.2307/1511361

Shute, V. J. (2008). Focus on formative feedback. Review of Educational Research, 78(1), 153-189. https://doi.org/10.3102/0034654307313795

Sinha, S., Rogat, T. K., Adams-Wiggins, K. R., \& Hmelo-Silver, C. E. (2015). Collaborative group engagement in a computer-supported inquiry learning environment. International Journal of Computer-Supported Collaborative Learning, 10(3), 273-307. https://doi.org/10.1007/ s11412-015-9218-y

Springer, L., Stanne, M. E., \& Donovan, S. S. (1999). Effects of small-group learning on undergraduates in science, mathematics, engineering, and technology: A meta-analysis. Review of Educational Research, 69(1), 21-51. https://doi.org/10.3102/00346543069001021

Sweller, J., van Merrienboer, J. J., \& Paas, F. G. (1998). Cognitive architecture and instructional design. Educational Psychology Review, 10(3), 251-296. https://doi.org/10.1023/A:1022193728205

van Merriënboer, J. J., \& Sweller, J. (2010). Cognitive load theory in health professional education: Design principles and strategies. Medical Education, 44(1), 85-93. https://doi.org/10.1111/j.13652923.2009.03498.x

Veletsianos, G., Reich, J., \& Pasquini, L. A. (2016). The life between big data log events: Learners' strategies to overcome challenges in MOOCs. AERA Open. https://doi.org/10.1177/2332858416657002

Weisz, J. D., Kiesler, S., Zhang, H., Ren, Y., Kraut, R. E., \& Konstan, J. A. (2007). Watching together: Integrating text chat with video. In Proceedings of the SIGCHI Conference on Human Factors in Computing Systems (pp. 877-886). https://doi.org/10.1145/1240624.1240756.

Wilkinson, D. M., \& Huberman, B. A. (2007). Cooperation and quality in Wikipedia. In Proceedings of the 2007 International Symposium on Wikis e Wikisym '07, (October) (pp. 157e164). https://doi. org/10.1145/1296951.1296968.

Wise, A. F., \& Cui, Y. (2018). Learning communities in the crowd: Characteristics of content related interactions and social relationships in MOOC discussion forums. Computers \& Education, 122, 221-242. https://doi.org/10.1016/j.compedu.2018.03.021

Yim, S., Wang, D., Olson, J., Vu, V., \& Warschauer, M. (2017). Synchronous Collaborative Writing in the Classroom: Undergraduates' Collaboration Practices and their Impact on Writing Style, Quality, and Quantity. In Proceedings of the 2017 ACM Conference on Computer Supported Cooperative Work and Social Computing (pp. 468-479). https://doi.org/10.1145/2998181.2998356 
Publisher's Note Springer Nature remains neutral with regard to jurisdictional claims in published maps and institutional affiliations.

Jamie Costley is an assistant professor in the Center for Sociology of Higher Education, Institute of Education at the Moscow Higher School of Economics. He is interested in a variety of topics related to how to improve learning in online environments, specifically in the areas of collaborative learning, cognitive load, and instructional design.

Mik Fanguy is a visiting professor in the School of Humanities and Social Sciences at the Korea Advanced Institute of Science and Technology (KAIST) in South Korea. His research interests include online collaborative writing and notetaking. 